\title{
An inter-hemispheric, statistical study of nightside spectral width distributions from coherent HF scatter radars
}

\author{
E. E. Woodfield ${ }^{1}$, K. Hosokawa ${ }^{2}$, S. E. Milan ${ }^{1}$, N. Sato ${ }^{3}$, and M. Lester ${ }^{1}$ \\ ${ }^{1}$ Department of Physics and Astronomy, University of Leicester, UK \\ ${ }^{2}$ Department of Geophysics, Graduate School of Science, Kyoto University, Japan \\ ${ }^{3}$ National Institute of Polar Research, Tokyo, Japan
}

Received: 22 February 2002 - Revised: 27 June 2002 - Accepted: 5 July 2002

\begin{abstract}
A statistical investigation of the Doppler spectral width parameter routinely observed by HF coherent radars has been conducted between the Northern and Southern Hemispheres for the nightside ionosphere. Data from the SuperDARN radars at Thykkvibær, Iceland and Syowa East, Antarctica have been employed for this purpose. Both radars frequently observe regions of high $\left(>200 \mathrm{~ms}^{-1}\right)$ spectral width polewards of low $\left(<200 \mathrm{~ms}^{-1}\right)$ spectral width. Three years of data from both radars have been analysed both for the spectral width and line of sight velocity. The pointing direction of these two radars is such that the flow reversal boundary may be estimated from the velocity data, and therefore, we have an estimate of the open/closed field line boundary location for comparison with the high spectral widths. Five key observations regarding the behaviour of the spectral width on the nightside have been made. These are (i) the two radars observe similar characteristics on a statistical basis; (ii) a latitudinal dependence related to magnetic local time is found in both hemispheres; (iii) a seasonal dependence of the spectral width is observed by both radars, which shows a marked absence of latitudinal dependence during the summer months; (iv) in general, the Syowa East spectral width tends to be larger than that from Iceland East, and (v) the highest spectral widths seem to appear on both open and closed field lines. Points (i) and (ii) indicate that the cause of high spectral width is magnetospheric in origin. Point (iii) suggests that either the propagation of the HF radio waves to regions of high spectral width or the generating mechanism(s) for high spectral width is affected by solar illumination or other seasonal effects. Point (iv) suggests that the radar beams from each of the radars are subject either to different instrumental or propagation effects, or different geophysical conditions due to their locations, although we suggest that this result is more likely to be due to geophysical effects. Point (v) leads us to conclude that, in general, the boundary between low and high spectral width will not be a
\end{abstract}

Correspondence to: E. E. Woodfield

(Emma.Woodfield@ion.le.ac.uk) good proxy for the open/closed field line boundary.

Key words. Ionosphere (auroral ionosphere; ionospheric irregularities)

\section{Introduction}

The Doppler spectral width parameter observed by the Super Dual Auroral Radar Network (SuperDARN) of coherent HF radars has been subject to increasing scrutiny. In particular, there are variations in spectral width as a function of latitude and time which may relate to the ionospheric footprint of magnetospheric regions. For example, regions of high and variable spectral width observed on the dayside are generally accepted as being associated with the low altitude cusp (Baker et al., 1990, 1995; Rodger et al., 1995; Pinnock et al., 1995; Andre et al., 1999, 2000a; Milan et al., 1999; Moen et al., 2001; Rodger, 2000). Similar regions of high and variable spectral width frequently occur on the nightside (Lewis et al., 1997; Dudeney et al., 1998; Lester et al., 2001; Woodfield et al., 2002a, b) and the debate over which magnetospheric regions these may represent is ongoing. There are two hypotheses regarding the magnetospheric origin of nightside regions of high spectral width, more specifically, regarding the sharp gradient between low spectral width $\left(<200 \mathrm{~ms}^{-1}\right)$, at lower latitudes, and high spectral width $\left(>200 \mathrm{~ms}^{-1}\right)$, at higher latitudes. The first proposal suggests a link between this spectral width gradient and the boundary between the Central Plasma Sheet (CPS) and Boundary Plasma Sheet (BPS) (Dudeney et al., 1998), while the second proposes that the spectral width gradient could represent the Open/Closed Field Line Boundary (OCFLB) (Lester et al., 2001).

There have been several suggestions for the physical explanation for the generation of regions of high and variable spectral width. André et al. (1999; 2000a, b) simulated the effect of a time-varying electric field, with frequencies of the order of 0.1 to $5 \mathrm{~Hz}$, on the complex autocorrelation func- 


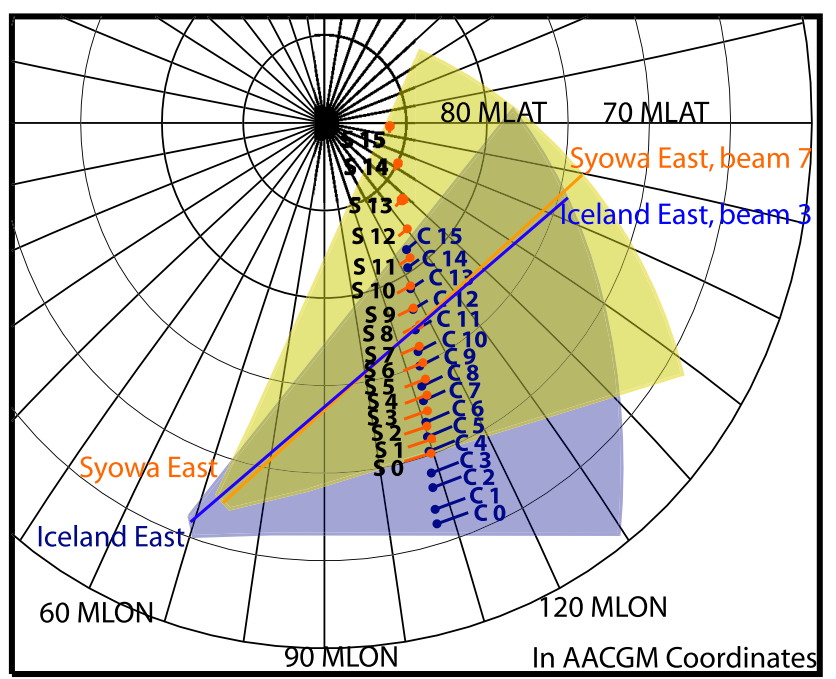

Fig. 1. A map in AACGM of the locations of the field-of-view of the Iceland East radar (blue) and the CUTLASS statistics summary range gates, $\mathrm{C} 0$ to $\mathrm{C} 15$. In yellow are the conjugately mapped fieldof-view of the Syowa East radar and its statistical summary range gates, S0 to S15.

tions (ACFs) derived from the HF coherent radars' pulse sequence and found that large spectral widths can be caused by such an electric field. The changing electric field causes the phase of the ACF to become nonlinear, which, in turn, generates several large peaks in the power spectrum of the signal (the Fourier transform of the ACF). The standard software used to process the radar measurements (FITACF), which fits the power spectrum parameters directly using the ACF, tends to overestimate the spectral width when there are many peaks of comparable power in the power spectrum. The estimated errors in the spectral width and line of sight velocity are also seen to rise where there are many peaks in the spectrum. André et al. (1999; 2000a, b) then linked the large spectral widths observed in the cusp (e.g. Baker et al., 1995) to electromagnetic wave activity $(0.2$ to $2.2 \mathrm{~Hz})$ observed by satellites passing through the cusp (e.g. Maynard et al., 1991; Matsuoka et al., 1993) and ground magnetometer data showing Pc1/Pc2 wave activity underneath the cusp (Menk et al., 1992; Dyrud et al., 1997). They conclude that Alfvén waves are likely to be the major energy source that causes the measurement of high spectral width in the cusp. Similar Alfvén waves may also, therefore, be responsible for the regions of high and variable spectral width observed on the nightside, and such wave activity has been observed throughout the auroral oval (Gurnett, 1991). No experimental study has yet demonstrated conclusively the relationship between wave activity and large spectral width on the nightside.

Other possible mechanisms for generating large HF spectral widths have been described by Schiffler et al. (1997) and Huber and Sofko (2000). Observations of the power spectra obtained from the low-latitude boundary layer using the maximum entropy method indicated the presence of many spectra with two main peaks. Therefore, they propose the presence of vortices in the plasma flow, smaller than the radar range cell and with a shorter lifespan than the integration time of the radar beam. Modelling of these vortices (Huber and Sofko, 2000) suggests that they would be capable of generating double-peak spectra. It is likely that FITACF overestimates the spectral width of the double-peak spectra. However, the simulations of the autocorrelation function generated by a small vortex $(\sim 5 \mathrm{~km})$ by André et al. (2000b) suggest that several vortices would be required within a radar range cell for more than one large peak in the power spectrum to be produced.

This paper investigates the statistical behaviour of the spectral width parameter measured by the Iceland East and Syowa East radars on the nightside, complementing work by Hosokawa et al. (2002) regarding the dayside. These radars are part of, and form a conjugate pair within, the SuperDARN HF radar network. The approximately meridional arrangement of the summary range gates employed in the statistics database, and described below, is used with the aim of determining the statistical location of the spectral width gradient, i.e. the transition from high to low spectral width, over time. This, in turn, may reveal something of the nature and origin of the spectral width gradient.

\section{SuperDARN}

The Super Dual Auroral Radar Network (SuperDARN) is a collection of high-frequency coherent scatter radars in both the Northern and Southern Hemispheres run cooperatively by many nations (Greenwald et al., 1995). Each radar uses a multi-pulse scheme to transmit radio waves along 16 beam directions, one at a time, with each beam returning information from a number of range gates ( 75 for Iceland East and 70 for Syowa East). In standard common mode the signal from each beam is integrated for $7 \mathrm{~s}$, with a gate length of $45 \mathrm{~km}$. The whole scan is synchronized to start at 2-min intervals, with each beam being $3.24^{\circ}$ wide. At nearer ranges the propagation is supported by the $\frac{1}{2}$-hop mode, and at further ranges by $1 \frac{1}{2}$-hop (Milan et al., 1997). Although the exact relationship between radar range and ground range is somewhat complex, the error in the range estimates for the radar beams is dependent upon the propagation mode; for $\frac{1}{2}$-hop the error is $\sim 15 \mathrm{~km}$, and for $1 \frac{1}{2}$-hop the error is $\sim 60 \mathrm{~km}$ (Yeoman et al., 2001). The data are routinely processed in real time by software (FITACF) used uniformly throughout the network to produce a set of parameters which include backscatter power, Doppler line of sight velocity and Doppler spectral width. The parameters are derived from the ACF of the returned signals for each range gate (Villain et al., 1987). A set of criteria are used to identify scatter from the ground (ground scatter is assumed to have a velocity $<50 \mathrm{~m} \mathrm{~s}^{-1}$ and spectral width $<20 \mathrm{~m} \mathrm{~s}^{-1}$ ). The fit is generally successful, although certain conditions giving rise to multi-peaked spectra may give rise to anomalies in the spectral width (Baker et al., 1995; André et al., 1999). 

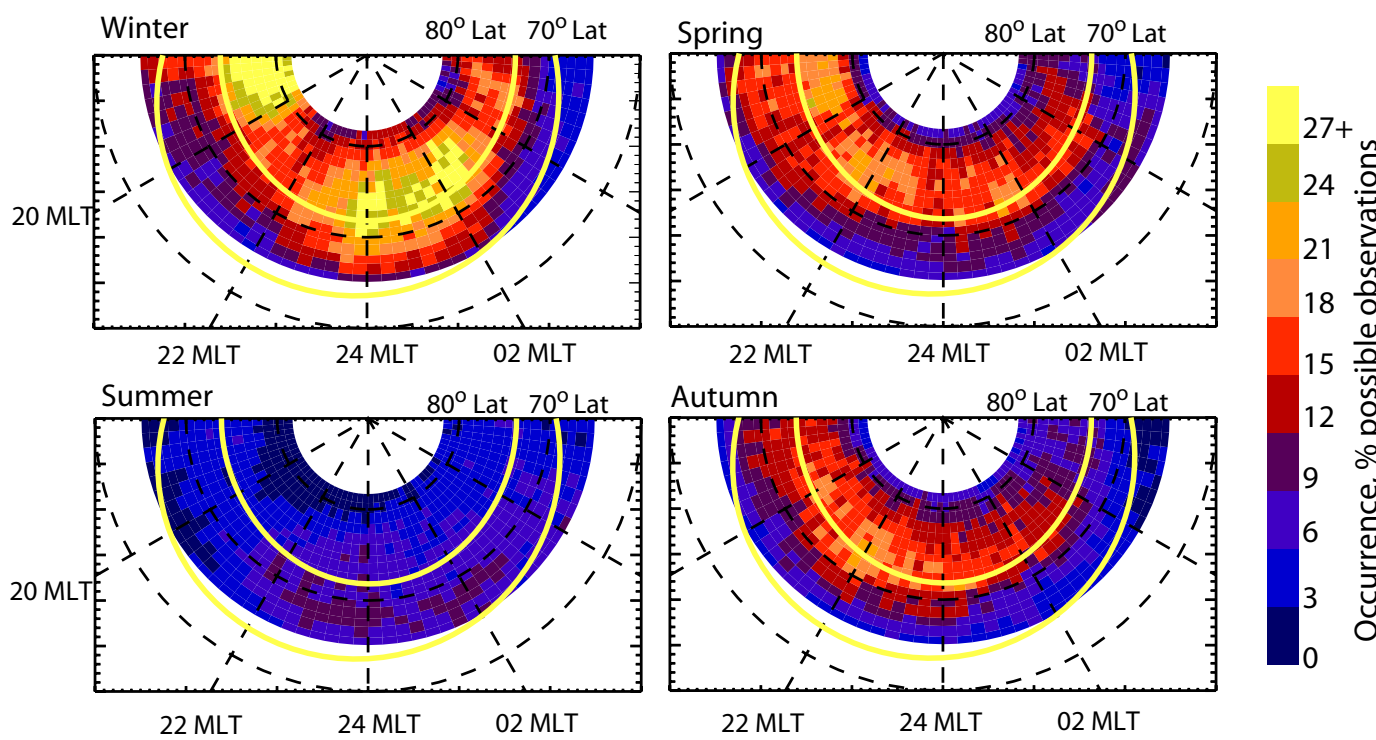

Fig. 2. Colour-coded plots of the data occurrence observed by the Iceland East radar as a function of Northern Hemisphere season, MLT and latitude for the three years of data. Each square of colour represents an interval of $15 \mathrm{~min}$ of MLT and one statistical summary point. The colour scale indicates the number of observations of ionospheric scatter above $3 \mathrm{~dB}$ as a percentage of the total possible observations in that season from the database used. A statistical auroral oval for a $K_{p}$ of 2 is overlaid for comparison.

The SuperDARN radars used in this investigation are Iceland East and Finland, situated in the Northern Hemisphere at Thykkvibær, Iceland $\left(64.49^{\circ} \mathrm{N}, 68.48^{\circ} \mathrm{E}\right)$ and Hankasalmi $\left(58.6^{\circ} \mathrm{N}, 104.9^{\circ} \mathrm{E}\right)$, respectively, and Syowa East situated in the Southern Hemisphere at Syowa Station, Antarctica $\left(66.09^{\circ} \mathrm{S}, 71.65^{\circ} \mathrm{E}\right)$. Altitude Adjusted Corrected Geomagnetic coordinates, AACGM, are used throughout this paper and are adapted from Baker and Wing (1989). The Iceland East and Syowa East radars form a conjugate pair, as shown in Fig. 1 (the Syowa East field-of-view has been mapped into the Northern Hemisphere using the IGRF95 model; Barton, 1997).

Each SuperDARN radar produces a large amount of data, making study of long-term variations in the observations problematic in terms of data storage requirements and processing time. To overcome this a representative subset of the observations from the Co-operative U. K. Twin Located Auroral Sounding System (CUTLASS) Finland and Iceland East radars are routinely stored in a "statistics database", which is kept on hard disk, allowing for easy analysis of the 6 years of radar measurements made to date (January 2002) in the common mode operations of the radars. The database resulting from this extra processing contains all the normal radar parameters but for only 16 summary radar cells. Such a database was originally introduced by Milan et al. (1997). In that study the 16 summary radar cells were taken from beam 7 of Iceland East, whereas in the present study we use the summary points originally identified in the Finland radar field-of-view. Thus, the summary points for Iceland East in this study are located approximately along a geomagnetic meridian, and the gates used are chosen for the large range of magnetic latitudes they encompass, $65^{\circ} \mathrm{N}$ to $81^{\circ} \mathrm{N}$.
The location of the summary points are given as $\mathrm{C} 0$ to $\mathrm{C} 15$ in Fig. 1. A similar set of summary range gates, spanning the latitude range $70^{\circ} \mathrm{S}$ to $86^{\circ} \mathrm{S}$ has been determined for the Syowa East radar data using the IGRF95 model (Barton, 1997) to find magnetically conjugate positions. In order to produce a more accurate comparison between the radar data sets, only mutual common time data (where the radars are run in the same mode) have been used for the interval 1 January 1998 to 31 December 2000. For the majority of the data the frequencies used in the common mode were consistent with Iceland East running in the frequency band from $10.2 \mathrm{MHz}$ to $10.7 \mathrm{MHz}$ twenty-four hours a day from January 1998 until October 2000. During November and December 2000, the daytime frequency (08:00 to 18:00 UT) for Iceland East was changed to the band from $12.1 \mathrm{MHz}$ to $12.2 \mathrm{MHz}$. Comparisons of the results using just 1998 and 1999 with those presented here show that this change in the frequency has no noticeable effect on the results. The Syowa East radar was run in the band $10.2 \mathrm{MHz}$ to $10.5 \mathrm{MHz}$ twenty-four hours a day for all the days, except the period from 6-10 February 1998, where the daytime frequency (06:00 to 18:00 UT) was from the $11.1 \mathrm{MHz}$ band. This also has very little appreciable effect on the results and the conclusions reached. Data with a received power below $3 \mathrm{~dB}$ are not used (to eliminate $\sim 75 \%$ of the noise), and data identified as ground scatter by the FITACF software have also been removed. The analysis presented here takes the form of occurrence distributions of spectral width. The data have been sorted into 15-min intervals of MLT and spectral width bins which are $20 \mathrm{~m} \mathrm{~s}^{-1}$ wide. The spectral width data have been restricted to the range 0 to $500 \mathrm{~m} \mathrm{~s}^{-1}$; this removes a further $\sim 20 \%$ of the observations. Since the fields of view of the radars do not 


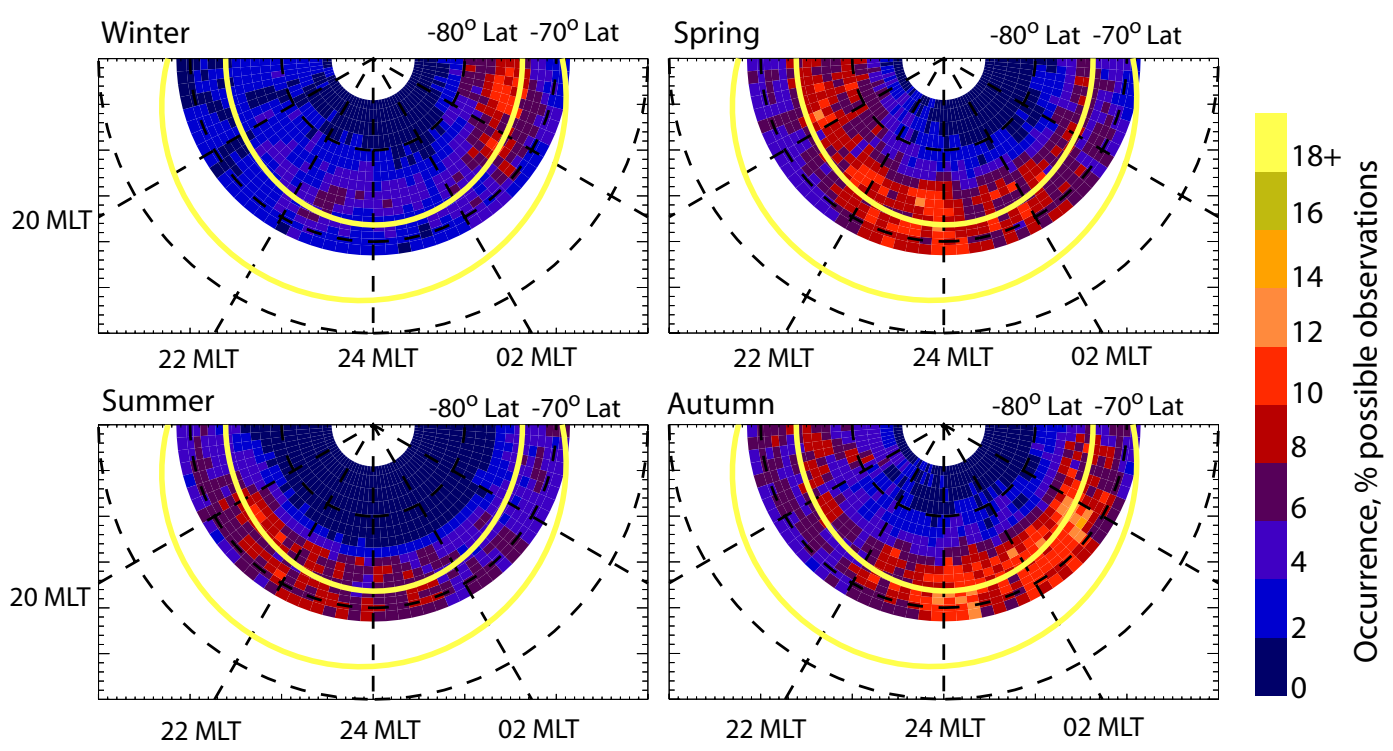

Fig. 3. Colour-coded plots of the data occurrence observed by the Syowa East radar as a function of Southern Hemisphere season, MLT and latitude for the three years of data. Each square of colour represents an interval of $15 \mathrm{~min}$ of MLT and one statistical summary point. The colour scale indicates the number of observations of ionospheric scatter above $3 \mathrm{~dB}$ as a percentage of the total possible observations in that season from the database used. A statistical auroral oval for a $K_{p}$ of 2 is overlaid for comparison.

overlap completely, there are some summary range gates that do not have a close conjugate partner. For Iceland East points C0 to C3 fall into this category, while for Syowa East points S12 to S15 have no conjugate partner. The summary points are located along beam 9 of the CUTLASS Finland radar, which is almost meridional to the magnetic pole. The aim of having the points aligned with a large variation in invariant latitude and a small variation in longitude $\left(\sim 15^{\circ}\right.$ for the points with conjugate partners) is that a long-term analysis of the latitudinal location of the spectral width gradient can be achieved.

\section{Statistical observations}

\subsection{Data occurrence}

Figure 2 shows the occurrence of ionospheric backscatter echoes over the three years of data used, split into seasons (winter consisting of November, December and January, spring taken as February, March and April, etc., for the Northern Hemisphere). Each colour-coded square represents a 15-min interval of MLT for each statistical point for Iceland East. The colour scale indicates the number of observations as a percentage of possible observations in that region and season over the three years of data presented. The Iceland East range gates coincident with the summary points vary between 39 and 48 , equivalent to the $1935 \mathrm{~km}$ to $2340 \mathrm{~km}$ range for normal mode operations. Thus, one expects mainly F-region scatter, with a mixture of $\frac{1}{2}$ and $1 \frac{1}{2}$ hop propagation to have originated from these locations. However, there may be some E-region contamination at these ranges resulting from $1 \frac{1}{2}$ hop propagation. An analysis of Iceland East backscatter similar to that conducted by Milan et al. (1997) shows a small population of Type 1 E-region scatter, identified by a low spectral width and a velocity which is close to the local ion acoustic speed, observed in all of the Iceland East summary points. An investigation of this Type 1 scatter for the data used indicates that the contamination of the F-region scatter is negligible. A similar analysis of the Syowa East data indicates no discernable Type 1 E-region scatter on the nightside. The largest number of observations tends to occur in winter, and the least in summer, agreeing with work by Milan et al. (1997). Milan et al. (1997) found that in summer most of the observations by the Iceland East radar involve $\frac{1}{2}$ hop propagation and as such, are in the range gates close to the radar. The summary points employed in the current study are all in the $1 \frac{1}{2}$ hop distance range and, therefore, the amount of data observed in the summer is less. The peak occurrence in winter is over $27 \%$ of the possible observations in the 15 -min interval and occurs between $75^{\circ} \mathrm{N}$ and $80^{\circ} \mathrm{N}$ from 18:00 MLT to 20:00 MLT, followed by a brief lull between 20:00 and 22:00 MLT. The number of observations then rises again, but at a lower latitude, with the maximum between $70^{\circ} \mathrm{N}$ and $75^{\circ} \mathrm{N}$, until the occurrence begins to fall off again from 04:00 MLT. The situation in spring is similar, although the maximum is smaller (approximately $24 \%$ of the possible observations) and the change in latitude is more gradual. Autumn is very similar to spring in the distribution of data observations. The maximum number of observations in the summer months is only $9 \%$ to $12 \%$, and this occurs mainly below $70^{\circ} \mathrm{N}$ and between 22:00 and 04:00 MLT.

The same analysis (except with Southern Hemisphere seasons) for the data from the Syowa East radar is presented in Fig. 3. The data distribution in the Southern Hemisphere 

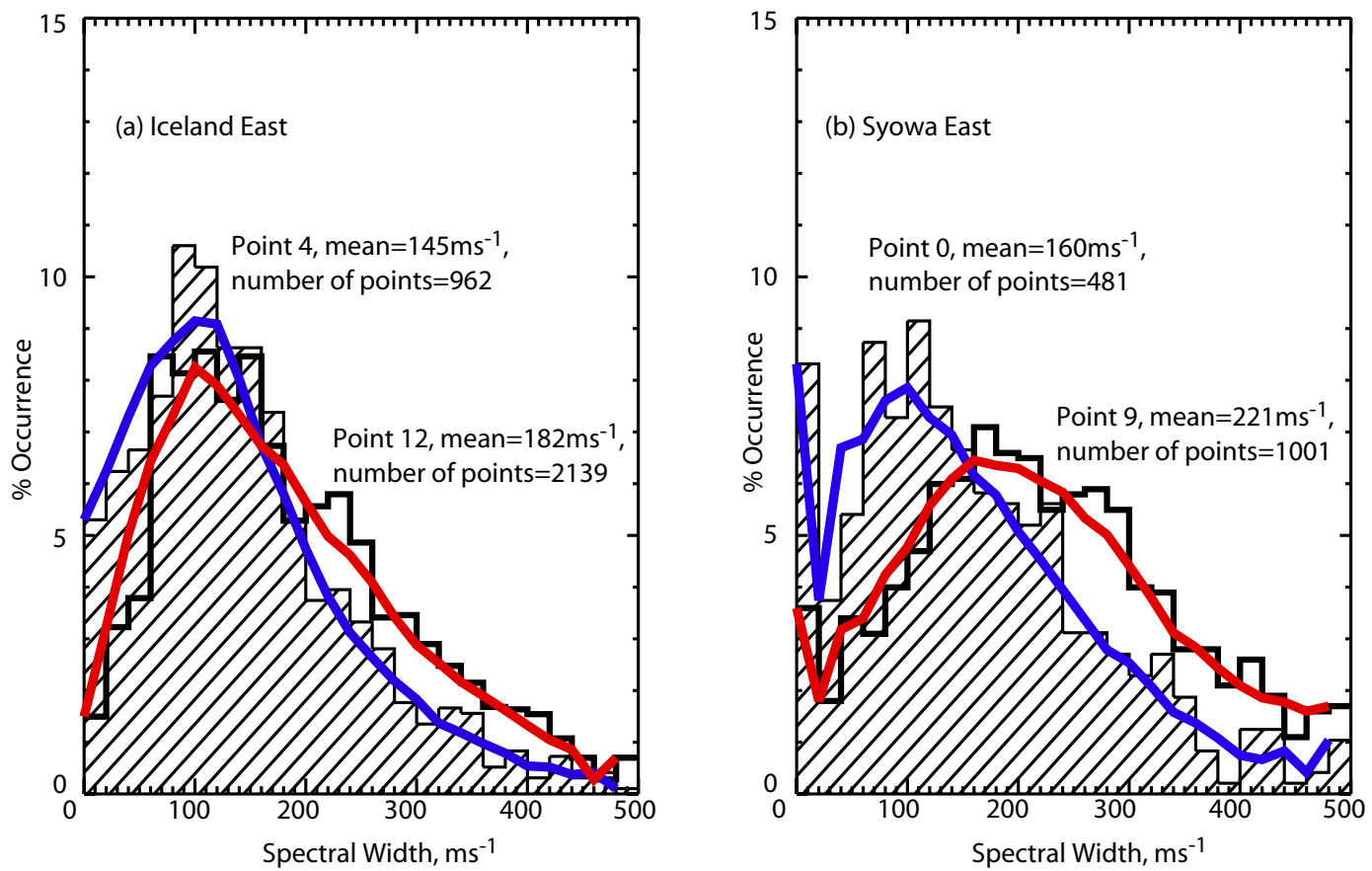

Fig. 4. Histograms showing typical examples of spectral width distributions from (a) Iceland East and (b) Syowa East. These are taken from the 04:00 to 06:00 MLT interval from the winter data from the respective hemispheres. The thick blue lines show the boxcar average of the shaded distributions and the thick red lines show the same for the unshaded distributions.

winter includes a similar peak at dawn to that of the Northern Hemisphere winter occurrence at dusk shown in Fig. 2. The differences between the data occurrence at the two radars is not the subject of this investigation; however, we suggest that they could be attributed to the different geographic locations of the two radars, leading to different plasma and propagation characteristics. The amount of data is low $(<4 \%$ of the possible observations) from 18:00 to 20:00 MLT in Fig. 3, when a region of maximum occurrence begins to become clear at around $75^{\circ} \mathrm{S}$. This continues until 03:00 MLT, when the occurrence increases to $10+\%$ at the peak. The situation in spring is very different, where the peak occurrence from 18:00 through to 06:00 MLT is over 10\%. The width of the maximum occurrence is approximately $7^{\circ}$, centred on $\sim 76^{\circ} \mathrm{S}$ from 18:00 to 21:00 MLT. After this there is a smooth, but rapid motion of the region of maximum occurrence equatorward with MLT, so that the region is centred nearer to $73^{\circ} \mathrm{S}$, and this remains until 06:00 MLT. The pattern in the summer months is relatively uniform, with very few data points poleward of $78^{\circ} \mathrm{S}$. Equatorward of this there is a band of larger occurrence varying between $6 \%$ to12\%. The autumn picture is similar to that in the spring, although the overall level of occurrence is lower.

Figures 2 and 3 show that the distribution of available data can be quite variable, although as will become apparent in the following sections, the spectral width distribution results are not biased by this fact. Only in the Southern Hemisphere summer, at the 4 summary points closest to the geomagnetic pole, does an absence of a reasonable amount of data cause significant problems in interpreting the spectral width results.

\subsection{Spectral width distributions}

Typical examples of histograms of spectral width occurrence produced from the statistics databases are presented in Fig. 4. The spectral widths are separated into two-hour intervals of MLT and the data are put into bins $20 \mathrm{~m} \mathrm{~s}^{-1}$ wide. The distribution for each summary point is normalised using the total number of points observed at that summary point. Figure $4 \mathrm{a}$ shows the distributions of spectral width for the Iceland East radar from summary points $\mathrm{C} 4\left(69.7^{\circ} \mathrm{N}\right)$ and $\mathrm{C} 12\left(77.8^{\circ} \mathrm{N}\right)$, for the Northern Hemisphere winter, 04:00 to 06:00 MLT. The shaded histogram, depicting the spectral width distribution for point $\mathrm{C} 4$, is narrower than the unshaded histogram representing the distribution for point $\mathrm{C} 12$. The standard deviations are $95 \mathrm{~m} \mathrm{~s}^{-1}$ and $106 \mathrm{~m} \mathrm{~s}^{-1}$, respectively, reflecting the narrower nature of the distribution at point $\mathrm{C} 4$. The means of the two distributions are also very different, $145 \mathrm{~m} \mathrm{~s}^{-1}$ and $182 \mathrm{~m} \mathrm{~s}^{-1}$ for points $\mathrm{C} 4$ and $\mathrm{C} 12$, respectively. Both distributions have a sufficient number of points to be considered in a statistical manner and both the distributions here resemble that found to be collocated with the low-altitude, low-latitude boundary layer (LLBL) (Baker et al., 1995, Fig. 8). The mode of all these distributions is below $150 \mathrm{~m} \mathrm{~s}^{-1}$, whereas the cusp distribution from Baker et al. (1995) has a mode of $\sim 200 \mathrm{~m} \mathrm{~s}^{-1}$. However, the more equatorward distribution from point $\mathrm{C} 4$ is more exponential in shape than that from point $\mathrm{C} 12$. The broader distribution also resembles the spectral width distribution (mode $230 \mathrm{~m} \mathrm{~s}^{-1}$ ) found in the Finland radar data above the poleward edge of the $630.0 \mathrm{~nm}$ optical emission by Lester et 


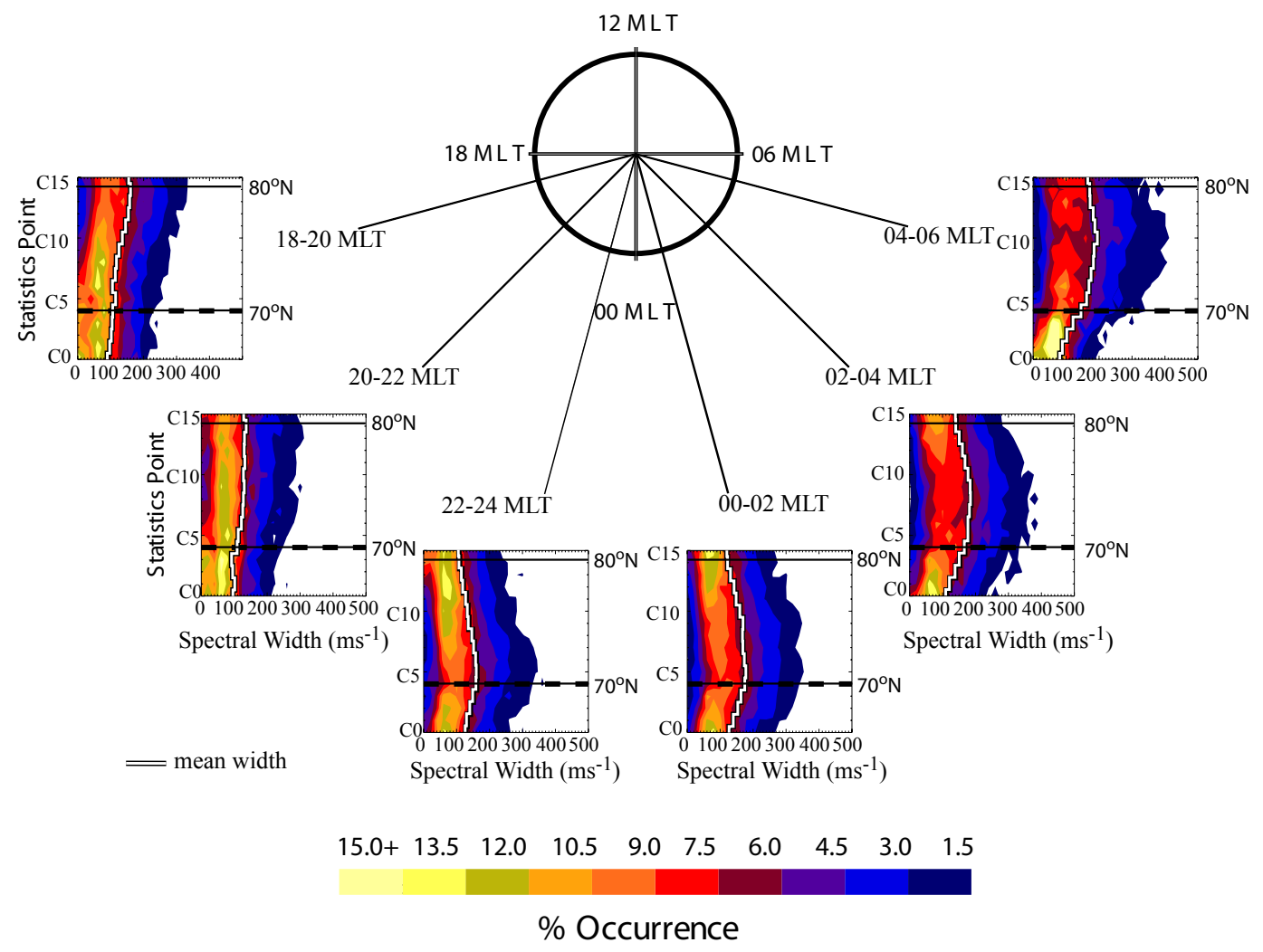

Fig. 5. Contour plots showing the Northern Hemisphere winter variation of spectral width distributions with MLT from Iceland East. The points below the black dashed line do not overlap with the conjugately mapped Syowa East summary points. The $70^{\circ} \mathrm{N}$ and $80^{\circ} \mathrm{N}$ positions are indicated by the thin black lines. The white on black lines show the mean spectral width value for each point on the lower axis scale. The colour scale indicates the occurrence at each width normalised to the total occurrence for each summary point.

al. (2001). Both distribution types were also seen in the interval studied by Woodfield et al. (2002a), where the broader distribution (mode $290 \mathrm{~m} \mathrm{~s}^{-1}$ ) occurred above the spectral width gradient found in the Finland data, and the narrower distribution (mode $30 \mathrm{~m} \mathrm{~s}^{-1}$ ) occurred below the spectral width gradient. However, the distributions in these case studies were more distinct than those of Fig. 4a, which may be a result of the averaging with the statistical database, or a result of the more zonal pointing direction of the Iceland East radar compared to the Finland radar.

The distributions in Fig. $4 \mathrm{~b}$ are from statistical points S0 and S9 of the Syowa East radar, for Southern Hemisphere winter (May, June and July), 04:00 to 06:00 MLT. These points are approximately conjugate to the summary points $\mathrm{C} 4$ and $\mathrm{C} 12$ from the Iceland East summary range gates (Fig. 1). The unshaded distribution from point $\mathrm{S} 9$ is more Gaussian shaped than that of $\mathrm{C} 12$ in Fig. $4 \mathrm{a}$, with a standard deviation of $117 \mathrm{~m} \mathrm{~s}^{-1}$ and a mean of $221 \mathrm{~m} \mathrm{~s}^{-1}$. This distribution resembles a cusp-type distribution following Baker et al. (1995). The distribution at point S0 is very similar to the conjugate distribution observed at point $\mathrm{C} 4$, though the mean and standard deviation for point $\mathrm{S} 0$ are much larger, $160 \mathrm{~m} \mathrm{~s}^{-1}$ and $109 \mathrm{~m} \mathrm{~s}^{-1}$, respectively, than the values at the conjugate point. There is also a noticeable peak in the range 0 to $20 \mathrm{~m} \mathrm{~s}^{-1}$ in both of the Syowa East distributions.
This is a common feature in the Syowa East data and is most likely caused by the inclusion of ground scatter that has been misidentified as ionospheric scatter. The broader distribution, with a larger mean at point S0 than that seen from the conjugate summary point $\mathrm{C} 4$ is also a regular feature. In general, we find that the spectral width distributions from Syowa East are broader, with larger standard deviations and higher means than for Iceland East. This is perhaps a common feature of spectral widths in the Northern and Southern Hemispheres as Milan and Lester (2001) suggested a similar asymmetry in the spectral width observations of the SuperDARN Goose Bay and Halley radars when observing the cusp region.

\subsubsection{Variation with latitude and magnetic local time}

The variation of the spectral width at Iceland East summary points as a function of latitude and magnetic local time is illustrated in Fig. 5. Here the distributions of spectral width for the Northern Hemisphere winter months, between 18:00 to 06:00 MLT on the nightside, are presented in bins with a two hour duration. The distributions are shown in the form of contour plots, with the colour scale representing the occurrence frequency of the spectral width values. The distribution for each summary point is self-normalised to the total 


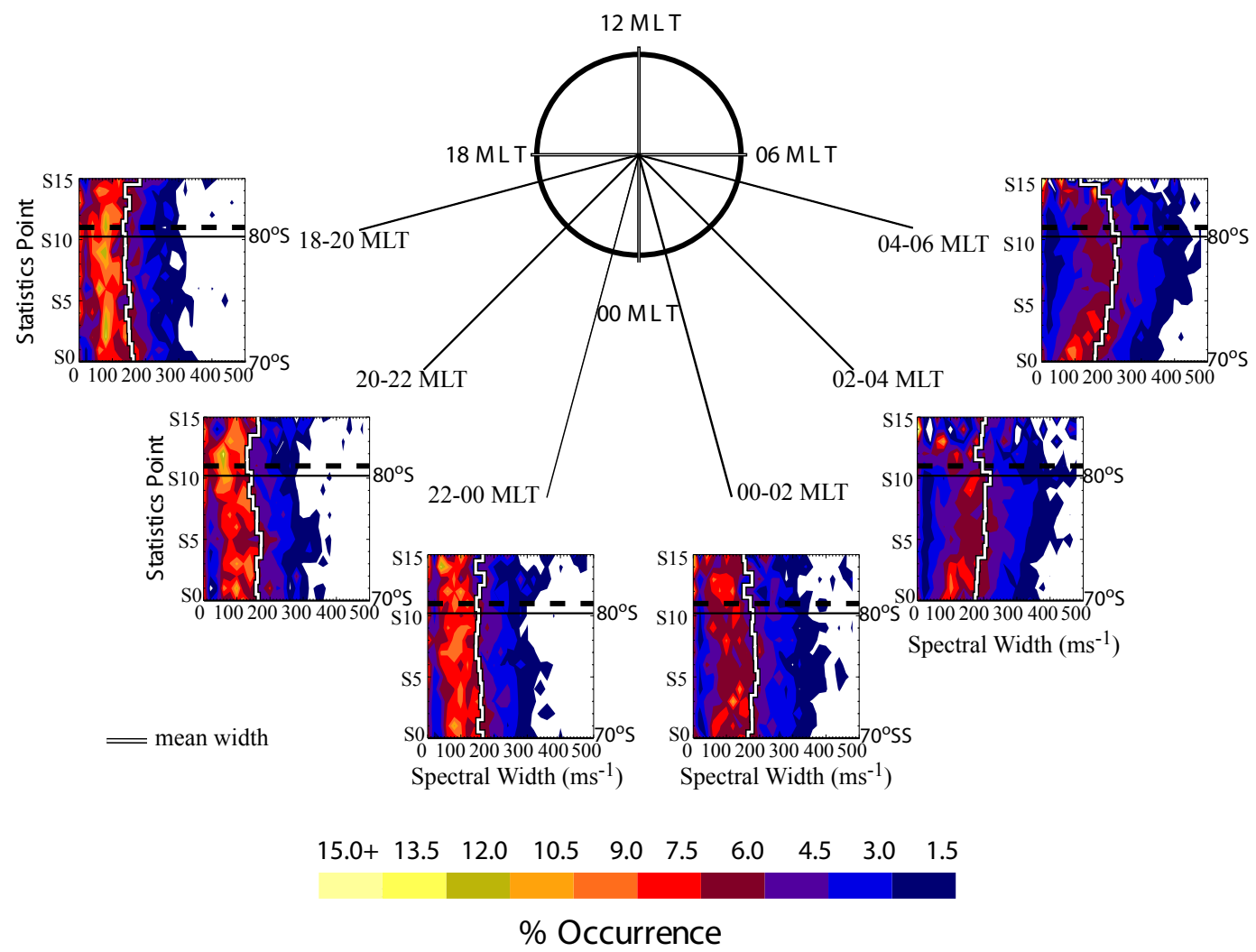

Fig. 6. Contour plots showing the Southern Hemisphere winter variation of spectral width distributions with MLT from Syowa East. The points above the black dashed line do not overlap with the Iceland East points. The $70^{\circ} \mathrm{S}$ and $80^{\circ} \mathrm{S}$ positions are indicated by the thin black lines. The white on black lines show the mean spectral width value for each point on the lower axis scale. The colour scale indicates the occurrence at each width normalised to the total occurrence for each summary point.

for that point. The dashed black line indicates the lower limit of the overlap with the Syowa East field-of-view. The thin, solid black lines indicate $70^{\circ} \mathrm{N}$ and $80^{\circ} \mathrm{N}$, as labelled. The white on black line shows the mean value for the spectral width distribution from each summary point, with values on the lower axis. The minimum number of points contributing to the spectral width distribution of a given summary point is $\sim 500$ and the maximum is $\sim 4000$. The $500 \mathrm{~ms}^{-1}$ limit set on the spectral width does not affect the contours, since there are so few points at or above this level. A comparison of Fig. 2, showing the occurrence of data points, and Fig. 5 shows that although the broadest spectral width distributions at first glance appear to follow the location of the most observations, the spectral width distributions in the 04:00 to 06:00 MLT bin of Fig. 5 are the most broad, but the maximum number of observations is in the 18:00 to 20:00 MLT region. Thus, the form of the spectral width distributions is not biased by the data occurrence. The shape described by the means of the distributions for each point varies as the MLT changes (the white on black line in Fig. 5). In the premidnight sector the mean value of the spectral width varies slowly between $\sim 90$ and $150 \mathrm{~ms}^{-1}$ across the 16 summary points. The distributions here are also, in general, quite narrow, even where the occurrence is large. The observations from 00:00 MLT onwards are somewhat different. The distri- butions become broader and the values of the means over the summary points have larger ranges, from 90 to $220 \mathrm{~m} \mathrm{~s}^{-1}$, with the spread greatest in the final nightside bin (04:00 to 06:00 MLT). In addition, the location of the largest value of the mean progresses northwards as the MLT increases in the post-midnight sector. Two distinct types of distribution emerge in the post-midnight sector, one narrow with a low mean, typically seen at low latitudes (e.g. summary point $\mathrm{C} 0$ in the 02:00 to 04:00 MLT bin), and the other broad with a higher mean, typically seen at higher latitudes (e.g. summary point C9 in the 02:00 to 04:00 MLT bin). These two types of distribution are shown in histogram form in Fig. 4a. The changeover point between these two forms of distribution in Fig. 5 represents the average position of the spectral width gradient for the Northern Hemisphere winter. The distributions and mean values suggest that the regions of high spectral width in the pre-midnight sector are comparatively less common events for the Iceland East radar.

The general trend appears to be that the separatrix between narrow, low-valued mean distributions and broader distributions with higher means $\left(>\sim 150 \mathrm{~m} \mathrm{~s}^{-1}\right.$ ) appears after 22:00 MLT, at which time it appears to be equatorward of point C5, becoming clearer towards dawn. A similar picture is true for the other three seasons, although in summer the distributions are much narrower overall; see the next section. 


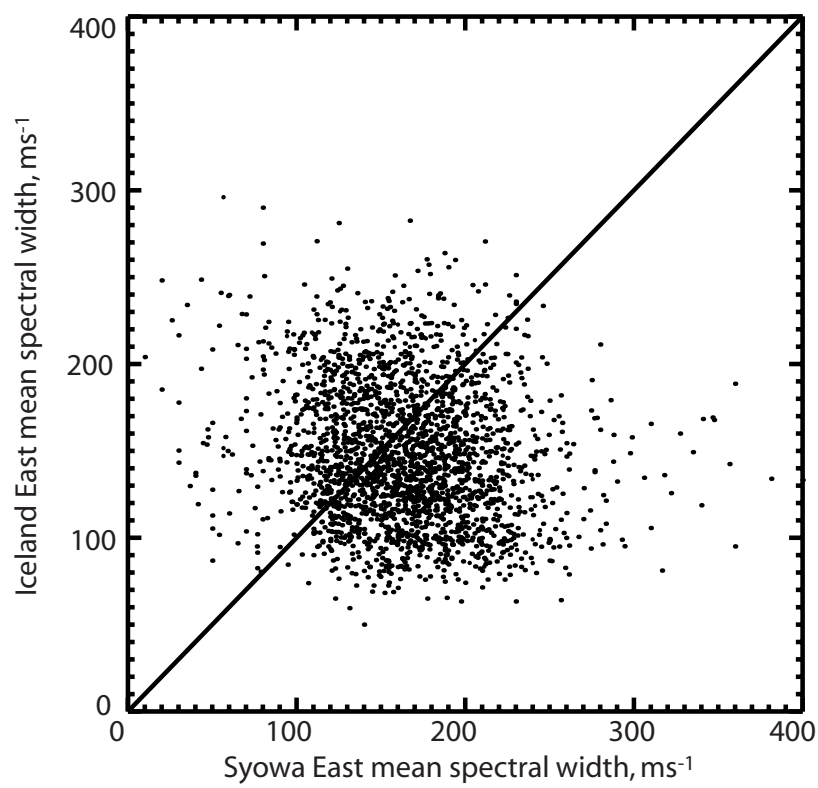

Fig. 7. Scatter plot of simultaneous and co-located mean spectral widths from the statistics databases of the Syowa East and Iceland East radars. The diagonal line represents a one-to-one relationship for comparison.

Figure 6 shows a similar analysis for the Syowa East summary range gates for the Southern Hemisphere winter (May, June, July). The dashed line shows the upper limit of the overlap with the Iceland East summary points. The thin, solid black lines indicate $70^{\circ} \mathrm{S}$ and $80^{\circ} \mathrm{S}$, as labelled, and the white on black line shows the mean spectral width. The field-of-view from point $\mathrm{S} 12\left(82.1^{\circ} \mathrm{S}\right)$ and polewards shows significantly less observed ionospheric scatter compared with points S11 and below (see Fig. 2). However, summary points S12 to S15 are polewards of the conjugate points of Iceland East and, therefore, this lack of data is not overly detrimental to this study. The distributions of spectral width observed by Syowa East are much broader, with higher means than those presented in Fig. 5 from Iceland East. The latitudinal variation in the mean is for the most part small. In the 18:00 to 20:00 MLT bin the mean spectral width decreases by approximately $40 \mathrm{~m} \mathrm{~s}^{-1}$ between S0 and S11, as the latitudes become closer to the pole. The situation is the same from 20:00 to 24:00 MLT. After midnight MLT the mean width shows no overall trend from $\mathrm{S} 0$ to $\mathrm{S} 11$, then from 02:00 to 06:00 MLT, the mean increases slightly from S0 to S11, particularly in the 04:00 to 06:00 MLT interval. The similarity to the Iceland East data is most noticeable in the change in the overall broadness of the spectral width distributions, with narrower distributions before midnight MLT and much broader ones as the morning sector is approached. A very similar set of contours is produced from the spring data, despite the different data occurrence between the two seasons (Fig. 3). This implies that the database is not biased (except at the latitudes closest to the pole, where there is very little data from the Syowa East radar).
Figure 7 presents a scatter plot of the simultaneous and conjugate mean spectral width values from the Syowa East and Iceland East statistics databases. The diagonal line represents the centre line for a one-to-one relationship. The main cluster of points is below this line, indicating that, on average, the Syowa East radar does have larger spectral widths, although not necessarily all the time. Keeping these differences in mind, the spectral width distributions in the region of overlap (Figs. 5 and 6) between the two sets of summary points show the same trend from narrower to broader distributions as 00:00 MLT is passed. The mean values increase overall from 22:00 MLT to 06:00 MLT, and the change in the shape of the distributions (as seen by looking at the modal values) is similar to that in Fig. 4.

In general, the separatrix between narrow and broad distributions is harder to see in the Syowa East spectral width distributions. Whether this is because the separatrix is simply equatorwards of the field-of-view or that it is not observable is unknown. Given the similarity of the trends between Syowa East and Iceland East, however, it is most likely to be the former explanation.

\subsubsection{Variation with season}

It has been suggested that the spectral width boundary is a proxy for the OCFLB. To test this we employ the flow reversal boundary (FRB) as another proxy of the OCFLB, assuming purely reconnection-driven convection (Lockwood et al., 1988) and compare its co-location with the spectral width distributions. The beams of the Iceland East radar point in a generally azimuthal direction; the line-of-sight velocity (1o-s) measurements are, therefore, ideally placed to locate the FRB of twin-cell convection of plasma around the polar cap. The measurements of 1-o-s velocity corresponding to the spectral widths already presented have also been collected into 15-min intervals of MLT. The mean velocity has then been calculated and identified as towards or away from the radar, ignoring the magnitude. The results are presented in the top four panels of Fig. 8, the red indicates westward and the blue indicates eastward flowing plasma. In all but the Northern Hemisphere summer, there is a clearly defined change in the direction of plasma flow with latitude. Statistical auroral ovals (Feldstein, 1963; Holzworth and Meng, 1975) for a $K_{p}$ value of 2 are overlaid for comparison (the average $K_{p}$ value over the three years was approximately 2 ). In winter the poleward edge of the auroral oval matches the FRB very closely, and the changeover between convection cells at the Harang discontinuity is over a small range of MLT, $\sim 30 \mathrm{~min}$. Although not shown here, the magnitude of the 1-o-s velocity in the changeover region is small, since the plasma motion here is mainly out of the polar cap and directly across the radar beams. The spring and autumn FRBs are also clear. The spring FRB, from 18:00 MLT to the changeover region, starting at $\sim 22: 00 \mathrm{MLT}$, is $\sim 4^{\circ}$ poleward of the inner boundary of the statistical auroral oval. However, the FRB from 24:00 MLT once again lines up with the poleward edge of the oval. A similar situation oc- 

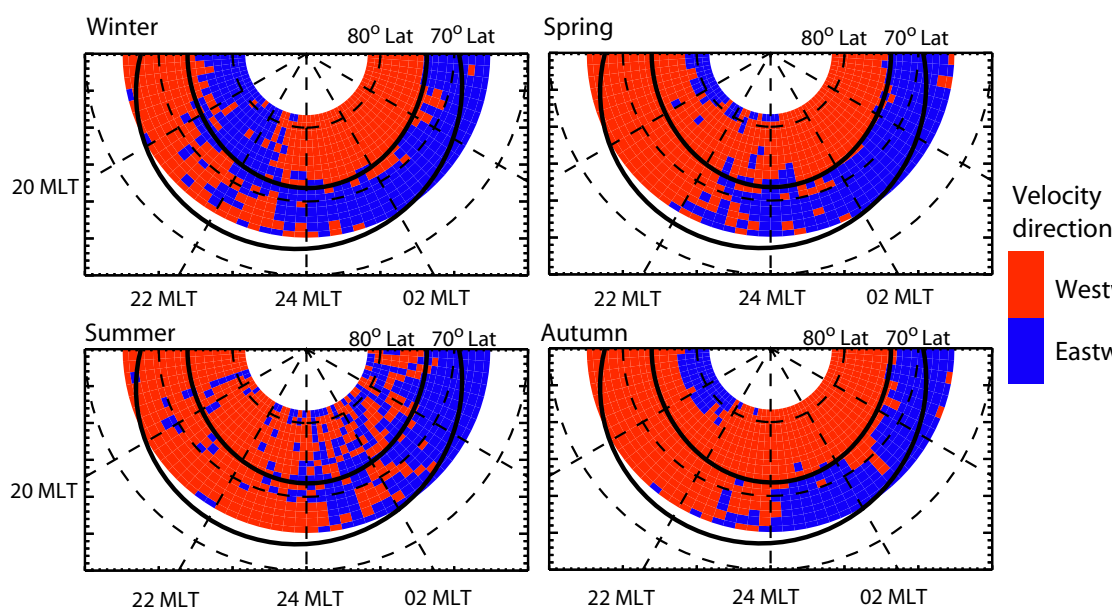

direction

Westwards

Eastwards
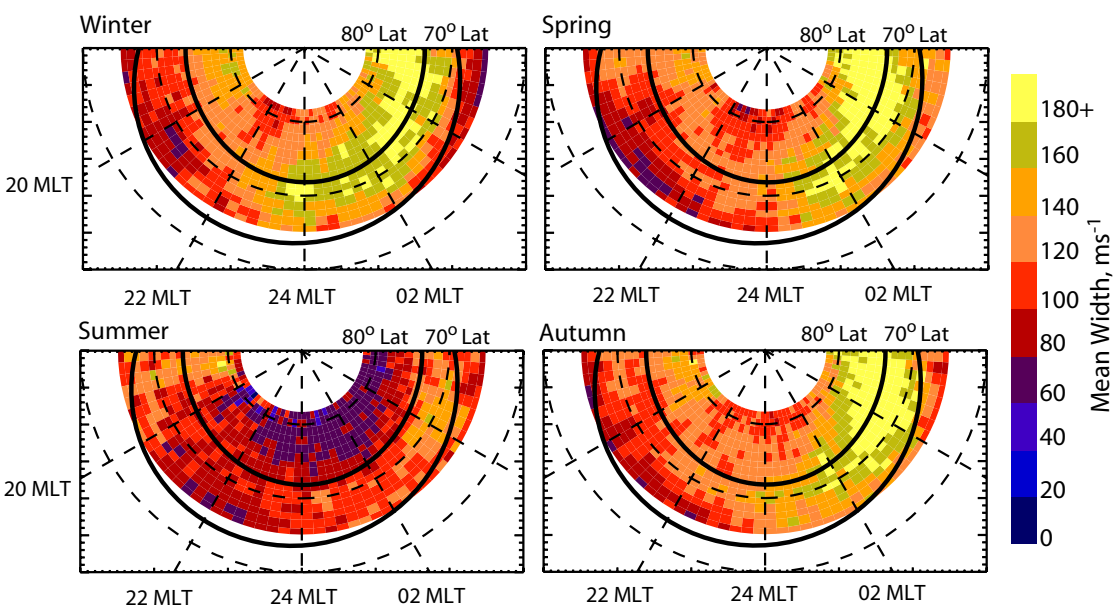

Fig. 8. The top four panels depict the direction of plasma flow observed by the near-azimuthal beams of the Iceland East radar. Red areas show westward moving plasma and blue areas eastward moving plasma. The data are separated into Northern Hemisphere seasons, 15-min MLT intervals and one square for each summary point. A statistical Feldstein auroral oval is overlaid for comparison. The bottom four panels show the similarly separated results for the mean spectral width, again with a statistical oval overlaid.

curs in the autumn. In the summer, the results of the analysis are unclear, probably due to the much smaller number of observations available. A comparison has been made with the statistical merged vectors available for the Iceland East, Finland pair of overlapping SuperDARN radars. The 1-o-s velocities for the overlapping summary points are combined to give two-dimensional vectors. Both Iceland East and Finland must have data at the relevant summary points for a twodimensional vector to be produced, making the question of how much data is necessary to see the general pattern more critical. This analysis is not shown, but indicates that the onedimensional depiction of the FRB in Fig. 8 is generally realistic for the two-dimensional vectors found using the overlapping radars. It would appear however, that the seasonal variation in the location of the one-dimensional FRB in the pre-midnight sector is not valid in the two-dimensional picture, and is, therefore, likely to be a product of using just one radar.
The bottom four panels of Fig. 8 represent the mean spectral widths in each season, again in 15-min intervals of MLT. The same statistical auroral ovals are overlaid on each of these panels. By examining the winter results first, we note that the highest mean values of spectral width, $160+\mathrm{m} \mathrm{s}^{-1}$, occur from $\sim 23: 00$ MLT through to 06:00 MLT, with a gradual rise in latitude from $\sim 70^{\circ} \mathrm{N}$ to $76^{\circ} \mathrm{N}$. Approximately half of the highest mean spectral widths occur within the auroral oval represented here, and since the FRB matches closely to the poleward edge of the oval, this means that half of the large spectral widths observed occurred on closed field lines, and half on open field lines. The gradual increase in latitude of the maximum in the mean spectral width appears to follow the motion of the auroral oval, so although it appears the two are somehow linked, it would seem that (at least from $\sim$ 22:00 MLT) the commonly observed spectral width gradient does not represent the OCFLB. A similar situation occurs in spring and autumn, although the start of the high spec- 

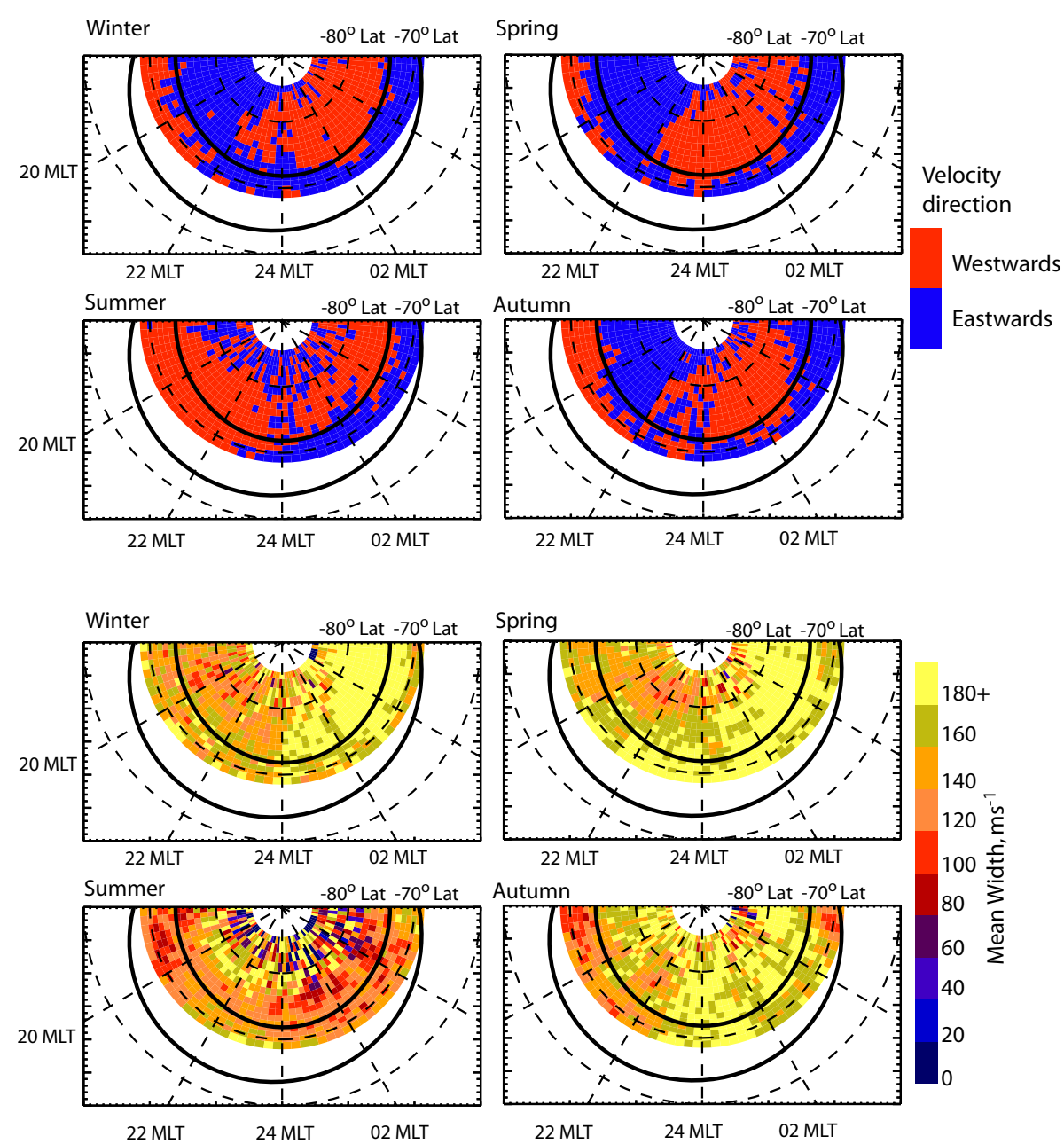

Fig. 9. The top four panels depict the direction of plasma flow observed by the near-azimuthal beams of the Syowa East radar. Red areas show westward moving plasma and blue areas eastward moving plasma. The data are separated into Southern Hemisphere seasons, 15-min MLT intervals and one square for each summary point. A statistical Feldstein oval is overlaid for comparison. The bottom four panels show the similarly separated results for the mean spectral width, again with a statistical oval overlaid.

tral width region is further around in MLT, at 01:00 MLT. The MLT sector between 18:00 and 21:00 MLT shows different behaviour from the post-midnight sector in winter, spring and autumn. Here the highest mean spectral widths seem to be mostly above the poleward edge of the auroral oval, with the maximum being lower than that in the post-midnight sector. The summer results show much lower widths throughout the nightside, even where the velocity results are clearest and the data occurrence is the largest.

Figure 9 presents a similar analysis for the Southern Hemisphere seasons. The Syowa East radar beams are also azimuthal, in general, and hence, we again see a clear indication of the location of the FRB in the top four panels of Fig. 9. The match to the velocity reversal in this case is close throughout the Southern Hemisphere winter, spring and autumn. The observations in the post-midnight sector of the summer data also line up closely to the auroral oval (there is more data here than for Iceland East, see Fig. 3). Unfortunately, for the time period used in the database, no over- lapping radar field-of-view was available for the Syowa East radar; therefore, no two-dimensional flow vectors are available for the Syowa East data during this time. Given the good relationship between the one- and two-dimensional flows for the Iceland East radar it seems reasonable to assume that the Syowa East one-dimensional data is a good substitute. The mean spectral widths shown in the bottom four panels are, in general, higher than those from Iceland East, as mentioned previously. Similar to the Iceland East analysis, the highest spectral widths tend to occur from a little before midnight to 06:00 MLT, although over a wider range of latitudes. Again, the summer widths are much lower, bearing in mind that the data poleward of $76^{\circ} \mathrm{S}$ is in very low abundance.

\section{Discussion}

The results presented in the previous section reveal four key points that require further comment. 
1. The spectral width gradient observed previously in case studies (e.g. Woodfield et al., 2002a) is seen to persist in statistical studies of the spectral width.

2. There is a variation in the latitude of the statistical gradient in the spectral width as MLT changes on the nightside. The highest widths seem to occur on both open and closed field lines, using the FRB obtained from the azimuthal velocity measurements as a guide.

3. There is a seasonal effect seen in the data, where the broader spectral width distributions do not appear to be present in the summer months.

4. The Southern Hemisphere spectral width values are typically larger than those from the Northern Hemisphere.

The change from low $\left(<200 \mathrm{~ms}^{-1}\right)$ to high $\left(>200 \mathrm{~ms}^{-1}\right)$ spectral width is a feature that occurs both on a case by case and a statistical basis in the nightside ionosphere. The FITACF software produces two distinct forms of spectral width: high and variable, and low, which can be identified using the distribution of spectral width over time. The low spectral width regions are characterised by narrow distributions dominated by a large peak close to $0 \mathrm{~ms}^{-1}$. The high and variable spectral width regions are characterised by a broader distribution, with a less prominent peak distinctly removed from $0 \mathrm{~ms}^{-1}$, and a larger mean (well above $\left.100 \mathrm{~ms}^{-1}\right)$. This is demonstrated in Fig. 4 of Woodfield et al. (2002a), which shows how the spectral width distribution over just 5 hours shows a trend from one to the other of these types of distribution described above. There is nearly always a distinct latitudinal gradient in the value of spectral width between the two regions in individual cases, and this often moves with time, thus, averaging over time (as in Fig. 4 of Woodfield et al., 2002a), the sharp gradient becomes a smoother change between the two types of distribution. This effect is prominent in the statistical distributions presented in this paper, which are greatly averaged; hence, the distinction between the idealised distributions for low and high spectral width becomes less obvious. Nevertheless, the trend from one type of distribution to the other is still apparent. The sharp gradient in the width seen in individual cases is not, in general, collocated with a sharp change in either backscatter power, l-o-s velocity or elevation angle. The broader spectral width distributions resemble those observed in the cusp, whereas the narrower distributions are more like those observed in the low-latitude boundary layer (Baker et al., 1995). This implies that a similar mechanism that causes high and variable spectral width in the cusp may also be manifest on the nightside.

Intense electric and magnetic field fluctuations of the order of $1 \mathrm{~Hz}$ have been observed over the auroral zone by low-altitude, polar-orbiting satellites (Gurnett et al., 1984; Gurnett, 1991; Dudeney et al., 1998). Two models for the generation of these 0.1 to $5 \mathrm{~Hz}$ fluctuations measured by lowaltitude satellites have been put forward. The first model assumes that the fluctuations are observed due to the motion of the satellite through a system of static field-aligned current structures (FACs) embedded in the ionosphere (Smiddy et al., 1980). This is a space/time ambiguity problem in the spacecraft data, not a wave in the ionosphere, and the scale size of these features would be small, approximately $200 \mathrm{~m}$, which is well below the size of a radar range cell. These FACs are capable of producing vortex patterns in the plasma flow around them (Lanzerotti et al., 1990 and references therein). Previous work with HF coherent radar spectra has attributed double-peaked spectra to vortices less than the scale size of the radar range cells $(\sim 45 \mathrm{~km})$, such as these static FACs could produce (Schiffler et al., 1997; Huber and Sofko, 2000). It is possible that double-peaked spectra may be observed with overestimated spectral widths, although simulations by André et al. (2000b) suggest that there would need to be several vortices smaller than the size of the radar range cell in order to cause high spectral widths.

The second model suggests that disturbances in the distant magnetosphere are transmitted to the ionosphere as Alfvén waves, and it is these waves that are the Pc1 and Pc2 frequency range fluctuations observed by the low-altitude satellites (e.g. Goertz and Boswell, 1979; Lysak and Dum, 1983). This would produce the kind of temporal electric field variation required for the proposed cusp mechanism of André and co-workers (1999; 2000a; 2000b).

The variation of the spectral width distributions observed with MLT indicates that the root cause of the high spectral width does not map to a constant magnetic latitude as MLT varies. This encourages the idea of using the spectral width boundary as an ionospheric proxy, since both the OCFLB and CPS/BPS boundaries move in latitude with MLT. The FRB identified using the azimuthal pointing directions of the two radars in Figures 8 and 9 shows that approximately half the highest spectral widths are likely to be on closed field lines in the MLT sector from 23:00 to 06:00 MLT. This implies that, in this sector at least, the spectral width gradient is unlikely to represent the OCFLB, since this would require all the highest values to be above the poleward edge of the auroral oval and the FRB. This agrees with case study results in this region of MLT (Woodfield et al., 2002a, b). The spectral widths prior to 23:00 MLT are lower in magnitude, and the distribution is such that the spectral width boundary observed between 18:00 and 23:00 MLT could reasonably represent the OCFLB, agreeing with Lester et al. (2001). This asymmetry of the spectral width magnitudes in the pre- and post-midnight sectors of the MLT indicates that the source region for generating high and variable spectral widths on the nightside is more prominent in the post-midnight sector.

A seasonal variation is observed in the magnitude of the mean spectral widths; in an attempt to explain this we try to identify here what seasonal influences might control this variation. One obvious seasonal factor to consider is the level of solar illumination. During the summer in the respective hemispheres, all the summary points are fully illuminated by the Sun at $300 \mathrm{~km}$ altitude on the nightside. The plasma density and, therefore, the plasma frequency is different in the summer. It is unlikely that changes in the propagation of the 
HF radar signals in summer are the cause of the decrease in the mean spectral widths. The decrease in the number of observations available during the summer is due to this reason, but the propagation itself would be unlikely to decrease the mean width unless the spectral width is height dependent. Woodfield et al. (2002a) examined the elevation angle data for the spectral width gradient case that they were investigating, and found that there was no change in elevation angle associated with the sudden change in spectral width values. This implies that the altitude of the observations is not a factor in the spectral width observations. Over the three years of data studied here there are enough data points available to assume that we see an accurate description of the summer spectral widths. It seems most likely that there is a seasonal variation in either the source of the high spectral widths, or how the different plasma conditions affect the propagation from the source. For example, if the high spectral widths are a result of a time-varying electric field (André et al., 1999; 2000a; 2000b), which originates from a down-tail disturbance in the magnetosphere and travels by Alfvén waves along magnetic field lines to the F-region ionosphere, then changes in the plasma properties along the path will change from season to season. If vortices are the mechanism, then the seasonal variation in the strength of FACs (e.g. Shue et al., 2001) is important. It is also possible, however, that the source region for this mechanism does not exist, or does not map to the same place in the summer months.

On a statistical basis the nightside spectral widths observed by the Syowa East radar are larger and more varied than those observed by its conjugate counterpart Iceland East. A similar situation exists on the dayside (Hosokawa et al., 2002). There are several possible explanations for this: (a) the difference in ionospheric conditions in the two hemispheres, both in terms of the propagation of the radar beams and the local conditions affecting any generating mechanisms, (b) an inter-hemispheric/seasonal difference in wave activity, (c) a variation in field-aligned current activity, (d) the difference in the dip-angle of the magnetic field lines for the two sets of summary range gates, or (e) instrumental noise levels. The fields-of-view of the two radars, although in conjugate geomagnetic positions, are not geographic mirror images of each other. The geographic latitude ranges for Syowa East and Iceland East are $63^{\circ} \mathrm{S}$ to $72^{\circ} \mathrm{S}$ and $73^{\circ} \mathrm{N}$ to $84^{\circ} \mathrm{N}$, respectively. As such, the level of solar illumination the summary points from each radar receive will be different in their respective seasons. This will likely cause a small difference in the propagation of the respective radar beams to the summary point locations, leading to a small difference in the height of the observations. However, even in the respective summers of each hemisphere, the Syowa East spectral width distributions are still broader, despite there being full (all be it at a slightly different zenith angle) illumination. Also, as mentioned previously, the spectral width appears to be independent of height. Points (b) and (c) amount to the same problem, where the mechanism for creating the high spectral width may itself vary between the hemispheres and also with season. Point d) relates to the difference in magnetic field line dip-angle, which is $\sim 10^{\circ}$, where the Iceland East summary points are subject to more vertical field lines. The dip-angle is important since this determines where and at what height the radar beam will be orthogonal to the magnetic field lines and hence, able to be backscattered by field-aligned irregularities. However, $10^{\circ}$ is a relatively small difference, outweighed by the typical error in the range estimation of a radar range cell at $1 \frac{1}{2}$ hops, which is $60 \mathrm{~km}$ (Yeoman et al., 2001). Instrumental effects, point (e), are an important consideration. Although the processing software used by both radars is identical throughout the data set, the noise level in the readings could affect the overall output. A power level of $3 \mathrm{~dB}$ and spectral width limit of $500 \mathrm{~ms}^{-1}$ was set in the analysis of the data we conducted, to eliminate approximately $95 \%$ of the data affected by low signal-to-noise ratios. We also performed a check on the comparative noise levels of the two radars and found that the amount of noise observed by the Syowa East radar was significantly lower than at Iceland East, likely due to the lack of local radio interference on Antarctica. If extra noise in the signals were the cause of the broader widths (by the introduction of powerful multiple peaks into the spectra), then we would expect to see higher values in the Iceland East data and not, as we have found, in the Syowa East data. It would, therefore, appear that the broader spectral widths in the Syowa East data are caused by a geophysical effect, but not one of radar propagation or processing of instrumental origin.

\section{Summary and conclusions}

A statistical study of SuperDARN radar spectral width data from the nightside in both hemispheres has been carried out using data from the Syowa East and Iceland East radars. These two radars often observe similar features in their spectral width data. This implies that the generating mechanism of high spectral width values is capable of travelling into both the Southern and Northern Hemispheres from some magnetospheric source region either on closed or open magnetic field lines. There is a definite latitudinal dependence of the spectral width distribution seen in both hemispheres that shows a statistical location of the spectral width gradient. The magnetic local time affects the spectral width distributions, notably in the location of the spectral width gradient, which reaches minimum latitude around magnetic midnight. Season also plays a part in the magnitude of the spectral width; in summer the spectral widths are decreased. The most marked difference between the Syowa East and Iceland East data is that the Syowa East spectral width distributions are, in general, broader and peaked at values greater than those of Iceland East. This is thought to be due to a geophysical rather than instrumental difference.

Acknowledgements. The authors wish to thank those involved in the deployment and operation of the CUTLASS HF radars run by the University of Leicester with joint funding from the UK Particle Physics and Astronomy Research Council (PPARC) grant number PPA/R/R/1997/00256, the Swedish Institute for Space Physics, Up- 
psala and the Finnish Meteorological Institute, Helsinki. The authors also wish to thank the Ministry of Education, Culture, Sports, Science and Techonology for supporting the Syowa HF radar systems and the 39th and 40th Japanese Antarctic Research Expeditions (JAREs) for carrying out the HF radar operations at Syowa. EEW is indebted to PPARC for a research studentship. This study is funded by a part of 'Ground Research for Space Utilization' promoted by NASDA and Japan Space Forum. KH is supported by the Grant in Aid for Scientific Research (A:11304029) from Japan Society for the Promotion of Science (JSPS).

The Editor in Chief thanks C. Hanuise and I. McCrea for their help in evaluating this paper.

\section{References}

André, R., Pinnock, M., and Rodger, A. S.: On the SuperDARN autocorrelation function observed in the ionospheric cusp, Geophys. Res. Lett., 26, 22, 3353-3356, 1999.

André, R., Pinnock, M., and Rodger, A. S.: Identification of the low-altitude cusp by Super Dual Auroral Radar Network radars: A physical explanation for the empirically derived signature, J. Geophys. Res., 105, A12, 27 081-27 093, 2000a.

André, R., Pinnock, M., Villain, J.-P., and Hanuise, C.: On the factors conditioning the Doppler spectral width determined from SuperDARN HF radars, Int. J. Geomag. Aeronomy, 2, 1, 77-86, 2000b.

Baker, K. B. and Wing, S.: A new magnetic coordinate system for conjugate studies at high latitudes, J. Geophys. Res., 94, 91399143, 1989.

Baker, K. B., Dudeney, J. R., Greenwald, R. A., Pinnock, M., Newell, P. T., Rodger, A. S., Mattin, N., and Meng, C.-I.: HF radar signatures of the cusp and low-latitude boundary layer, J. Geophys. Res., 100, A5, 7671-7695, 1995.

Baker, K. B., Greenwald, R. A., Ruohoniemi, J. M., Dudeney, J. R., Pinnock, M., Newell, P. T., Greenspan, M. E., and Meng, C.I.: Simultaneous HF-radar and DMSP observations of the cusp, Geophys. Res. Lett., 17, 11, 1869-1872, 1990.

Barton, C. E.: International Geomagnetic Reference Field: The Seventh Generation, J. Geomag. Geoelectr., 49, 123-148, 1997.

Dudeney, J. R., Rodger, A. S., Freeman, M. P., Pickett, J., Scudder, J., Sofko, G., and Lester, M.: The nightside ionospheric response to IMF $B_{y}$ changes, Geophys. Res. Lett., 25, 14, 2601-2604, 1998.

Dyrud, L. P., Engebretson, M. J., Posh, J. L., Hughes, W. J., Fukunishi, H., Arnoldy, R. L., Newell, P. T., and Horne, R. B.: Ground observations and possible source regions of two types of PC12 micropulsation at very high latitudes, J. Geophys. Res., 102, 27 011-27 027, 1997.

Feldstein, Y. I.: On morphology of auroral and magnetic disturbances at high latitudes, Geomag. Aeron., 3 , 183-192, 1963.

Goertz, C. K. and Boswell, R. W.: Magnetosphere-Ionosphere Coupling, J. Geophys. Res., 84, 7239-7246, 1979.

Greenwald, R. A., Baker, K. B., Dudeney, J. R., Pinnock, M., Jones, T. B., Thomas, E. C., Villain, J.P., Cerisier, J.C., Senior, C., Hanuise, C., Hunsucker, R. D., Sofko, G., Koehler, J., Nielsen, E., Pallinen, R., Walker, A. D. M., Sato, N., and Yamagishi, H.: DARN/SuperDARN: A global view of the dynamics of the highlatitude convection, Space Sci. Rev., 71, 761-796, 1995.

Gurnett, D. A.: Auroral Plasma Waves, in Auroral Physics, (Eds) Meng, C.-I., Rycroft, M. J., and Franck, L. A., Cambridge Univ. Press, New York, Ch. IV-6, pp. 241-254, 1991.
Gurnett, D. A., Huff, R. L., Menietti, J. D., Burch, J. L., Winningham, J. D., and Shawan, S. D.: Correlated Low-Frequency Electric and Magnetic Noise Along the Auroral Field Lines, J. Geophys. Res., 89, 8971-8985, 1984.

Holzworth, R. H. and Meng, C.-I.: Mathematical representation of the auroral oval, Geophys. Res. Lett., 2, 377-380, 1975.

Hosokawa, K., Woodfield, E. E., Lester, M., Milan, S. E., Yukimatu, A. S., and Sato, N.: Statistical Characteristics of Spectral Width as Observed by the Conjugate SuperDARN Radars, Ann. Geophysicae, in press, 2002.

Huber, M. and Sofko, G. J.: Small-scale vortices in the high-latitude F-region, J. Geophys. Res., 105, 20 885-20 897, 2000.

Lanzerotti, L. J., Wolfe, A., Trivedi, N., Maclennan, C. G., and Medford, L. V.: Magnetic Impulse Events at high Latitudes: Magnetopause and Boundary Layer Plasma Processes, J. Geophys. Res., 95, 97-107, 1990.

Lester, M., Milan, S. E., Besser, V., and Smith, R.: A Case Study of HF Radar Spectra and $630.0 \mathrm{~nm}$ Auroral Emission in the Pre Midnight Sector, Ann. Geophysicae, 19, 327-339, 2001.

Lewis, R. V., Freeman, M. P., Rodger, A. S., Reeves, G. D., and Milling, D. K.: The electric field response to the growth phase and expansion phase onset of a small isolated substorm, Ann. Geophysicae, 15, 289-299, 1997.

Lockwood, M., Cowley, S. W. H., Todd, H., Willis, D. M., and Clauer, C. R.: Ion flows and heating at a contracting polar-cap boundary, Planet. Space Sci., 36, 11, 1229-1253, 1988.

Lysak, R. L. and Dum, C. T.: Dynamics of MagnetosphereIonosphere Coupling Including Turbulent Transport, J. Geophys. Res., 88, 365-380, 1983.

Matsuoka, A., Tsuruda, K., Hayakawa, H., Mukai, T., Nishida, A., Okada, T., Kaya, N., and Fukunishi, H.: Electric field fluctuations and charged particle precipitation in the cusp, J. Geophys. Res., 98, 11 225-11 234, 1993.

Maynard, N. C., Aggson, T. L., Basinka, E. M., Burke, W. J., Craven, P., Peterson, W. K., Suguira, M., and Weimer, D. R.: Magnetospheric boundary dynamics: DE-1 and DE-2 observations near the magnetopause and cusp, J. Geophys. Res., 96 3505-3522, 1991.

Menk, F. W., Fraser, B. J., Hansen, H. J., Newell, P. T., Meng, C.I., and Morris, R. J.: Identification of the magnetospheric cusp and cleft using PC1-2 ULF pulsations, J. Atmos. Terr. Phys., 54, 1021-1042, 1992.

Milan, S. E. and Lester, M.: Interhemispheric differences in the HF radar signature of the cusp region A review through the study of a case example, Adv. Polar Upper Atmos. Res., 15, 159-177, 2001.

Milan, S. E., Lester, M., Cowley, S. W. H., Moen, J., Sandholt, P. E., and Owen, C. J.: Meridian-scanning photometer, coherent HF radar, and magnetometer observations of the cusp: a case study, Ann. Geophysicae, 17, 159-172, 1999.

Milan, S. E., Yeoman, T. K., Lester, M., Thomas, E. C., Jones, T. B.: Initial backscatter occurrence statistics from the CUTLASS HF radars, Ann. Geophysicae, 15, 703-718, 1997.

Moen, J., Carlson, H. C., Milan, S. E., Shumilov, N., Lybekk, B., Sandholt, P. E., and Lester, M.: On the collocation between dayside auroral activity and coherent HF radar backscatter, Ann. Geophysicae 18, 1531-1549, 2001.

Pinnock, M., Rodger, A. S., Dudeney, J. R., Rich, F., and Baker, K. B.: High spatial and temporal resolution observations of the ionospheric cusp, Ann. Geophysicae, 13, 919-925, 1995.

Rodger, A. S., Mende, S. B., Rosenberg, T. J., and Baker, K. B.: Simultaneous optical and HF radar observations of the ionospheric 
cusp, Geophys. Res. Lett., 22, 2045-2048, 1995.

Rodger, A. S.: Ground-based imaging of Magnetospheric boundaries, Adv. Space Res., 25, 7/8, 1461-1470, 2000.

Schiffler, A., Sofko, G., Newell, P. T., and Greenwald, R.: Mapping the outer LLBL with SuperDARN double-peaked spectra, Geophy. Res. Lett., 24, 3149-3152, 1997.

Shue, J.-H., Newell, P. T., Liou, K., and Meng, C.-I.: The quantitative relationship between auroral brightness and solar EUV Pedersen conductance, J. Geophys. Res., 106, 5883-5894, 2001.

Smiddy, M., Burke, W. J., Kelley, M. C., Saflekos, N. A., Gussenhoven, M. S., Hardy, D. A., and Rich, F. J.: Effects of HighAltitude Conductivity on Observed Convection Electric Fields and Birkeland Currents, J.Geophys. Res., 85, 6811-6818, 1980.

Villain, J.-P., Greenwald, R. A., Baker, K. B., and Ruohoniemi,
J. M.: HF radar observations of E-region plasma irregularities produced by oblique electron streaming, J. Geophys. Res., 92, 12327-12 342, 1987.

Woodfield, E. E., Davies, J. A., Eglitis, P., and Lester, M.: High and variable spectral width in the pre-dawn sector: A case study involving CUTLASS, EISCAT, ESR and optical data, Ann. Geophysicae, 20, 501-509, 2002a.

Woodfield, E. E., Davies, J. A., Lester, M., Yeoman, T. K., Eglitis, P., and Lockwood, M.: Nightside studies of coherent HF radar spectral width behaviour, Ann. Geophysicae, in press, 2002b.

Yeoman, T. K., Wright, D. M., Stocker, A. J., and Jones, T. B.: An evaluation of range accuracy in the Super Dual Auroral Radar Network over-the-horizon HF radar systems, Radio Science, 36, 4, 801-813, 2001. 